\title{
Nanocellulose Bulk Material Prepared by Steam Treatment and Hot Press Molding: Material Processing and Machining Test
}

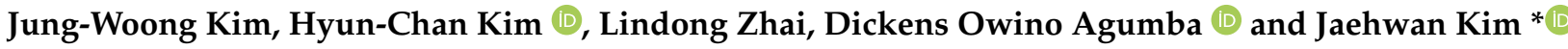 \\ Creative Research Center for Nanocellulose Future Composites, Department of Mechanical Engineering, \\ Inha University, 100 Inha-Ro, Michuhol-Ku, Incheon 22212, Korea; jw6294@naver.com (J.-W.K.); \\ kim_hyunchan@naver.com (H.-C.K.); duicaofei@naver.com (L.Z.); owinodickens@gmail.com (D.O.A.) \\ * Correspondence: jaehwan@inha.ac.kr; Tel.: +82-32-874-7325
}

check for updates

Citation: Kim, J.-W.; Kim, H.-C.; Zhai, L.; Agumba, D.O.; Kim, J. Nanocellulose Bulk Material Prepared by Steam Treatment and Hot Press Molding: Material Processing and Machining Test. Crystals 2021, 11, 853. https:// doi.org/10.3390/cryst11080853

Academic Editors: Claudia Graiff and Marianna Potenza

Received: 26 June 2021

Accepted: 20 July 2021

Published: 22 July 2021

Publisher's Note: MDPI stays neutral with regard to jurisdictional claims in published maps and institutional affiliations.

Copyright: (c) 2021 by the authors. Licensee MDPI, Basel, Switzerland. This article is an open access article distributed under the terms and conditions of the Creative Commons Attribution (CC BY) license (https:// creativecommons.org/licenses/by/ $4.0 /)$.

\begin{abstract}
Nanocellulose (NC) has been spotlighted as a new building block of future materials since it has many advantages, such as being lightweight and environment-friendly and having high mechanical properties and heat resistance. However, the use of NC requires an upscale manufacturing process to maintain its advantageous properties. Herein, the process of assembling NC into a macro-scale bulk material was developed through a combination of steam treatment and hot press molding. The steam treatment was applied to an NC paste to energize the hydroxyl groups in the cellulose, followed by two stages of hot press molding, which helped in the self-assembly of NC without adhesives. Cellulose nanocrystals were used as the NC, and circular disk shape specimens were prepared. The mechanical properties of the prepared bulk material were higher than typical engineering plastics. In addition, an end mill machining test of the NC bulk material showed its machinability. This paper showed the processing feasibility of NC bulk material, which can substitute plastics.
\end{abstract}

Keywords: nanocellulose; bulk material; hot pressing; molding

\section{Introduction}

Materials are ingrained in our culture, and they play a crucial role in our way of life and the well-being and security of humankind. They are cycled in nature. Raw materials are taken from nature, converted into bulk materials, and substantially fabricated into engineering materials, such as structural steel, concrete, plastics, and plywood [1]. Eventually, after servicing, these materials find their way back to nature by disposal or reenter the cycle by being reprocessed. An essential aspect of the materials cycle is that it reveals many strong interactions among materials, energy, and the environment, which should be taken into account in the technological assessment. These considerations are becoming critical because of shortages in energy and materials. Nowadays, environmental concerns such as plastic pollution have become an urgent environmental issue as the rapidly increasing production of plastic products overwhelms the world's ability to handle them. Production of plastics has increased exponentially, from 2.3 million tons in 1950 to 448 million tons in 2015. This production is expected to double by 2050 [2]. Plastic takes decades to decompose after being discarded and puts a heavy burden on the environment, as it is manufactured with nonrenewable resources such as oil. Many efforts have been made to develop environment-friendly materials made from renewable resources [3].

Cellulose, one of the most abundant renewable materials, is derived from biomass such as plants, bacteria, and marine plants. Within an individual cellulose elementary fibril, cellulose molecular chains are hierarchically organized into crystalline and amorphous regions [4]. This hierarchical structure of cellulose can be divided into cellulose nanocrystal (CNC), composed of a cellulose crystalline region, and cellulose nanofiber (CNF), where amorphous and crystalline regions are connected to form the nanofiber. $\mathrm{CNC}$ has a low density, high aspect ratio, high mechanical properties [5], low toxicity, and a surface 
containing hydroxyl groups that can be chemically modified [6-8]. CNC and CNF are generally called nanocellulose (NC) [9]. NC has many advantages; it has high mechanical properties and is lightweight, environment-friendly, renewable, and abundant. It has been widely studied in various fields, such as packaging, heat management, flexible electronics, and energy storage systems [10-13]. NC can be a building block for new materials for future technologies [14]. However, because of its nano size, extending its advantages for large-size bulk material is challenging in NC research with proper processing [15].

Previously, compression molding of micro-sized cellulose powder has been studied. As a result of compression-molded commercial $\alpha$-cellulose powder, a smooth, plastic-like surface was made, and its Young's modulus and tensile strength were 1.6 GPa and $21.2 \mathrm{MPa}$, respectively [16]. Furthermore, research on the thermo-pressing of CNF produced via a combination of enzymatic activity was also reported, with improved mechanical properties such as bending modulus of $5 \mathrm{GPa}$ and bending stress of $90 \mathrm{MPa}$ [17]. Recently, the additive manufacturing of cellulose has been studied. Three-dimensional objects were 3D-printed utilizing wood flour microparticles dispersed in CNCs and xyloglucan matrix [18]. In the printed object, a wood waste product was glued with extracted wood products to substitute for pristine wood. However, the maximum Young's modulus and compression strength of the 3D-printed material was $44 \mathrm{MPa}$ and $8 \mathrm{MPa}$, respectively. Although 3D printing is a convenient technique for producing $3 \mathrm{D}$ objects of cellulose material, the mechanical properties of the 3D objects are far behind the anticipated targets of NC. In addition, the use of binders in forming 3D objects made of cellulose may not be cost-effective. Thus, an economical approach for forming NC 3D objects is necessary.

This research aims to investigate the feasibility of NC bulk material, which can substitute bulk plastics. Instead of using 3D printing, a hot press molding technique combined with steam treatment was adopted to form the NC bulk material. Cellulose has many hydroxyl groups, which can form hydrogen bonds. Hydrogen bond formation is a wellknown phenomenon in paper processing. Paper is formed by networking randomly dispersed wood fibers with moisture and under hot pressing.

Similarly, NC bulk material can be formed by applying high energy, such as heat, and pressing. Figure 1 shows the schematic of the proposed NC bulk material processing. At first, steam treatment is applied to NC paste to energize the hydroxyl groups in cellulose, followed by two stages of press molding, which help in the self-assembly of NCs by heating and hot pressing without any adhesives $[19,20]$. It was found that wood waste can be turned into a fibrous structure suitable for manufacturing plate materials because of the hydrothermal process using steam treatment [19]. In other words, the hydrothermal process can increase cellulose's liquidity, thereby increasing its moldability [21]. In this study, CNC was used for the NC bulk material. Pressing parameters of the NC bulk materials were investigated in this paper in terms of hand-pressing temperature, time, and hot-pressing condition. Furthermore, machining of the prepared NC bulk material is essential to manufacture components. Thus, the machining conditions of end milling were investigated by measuring the specimens' surface roughness and the heat generated during the machining. 


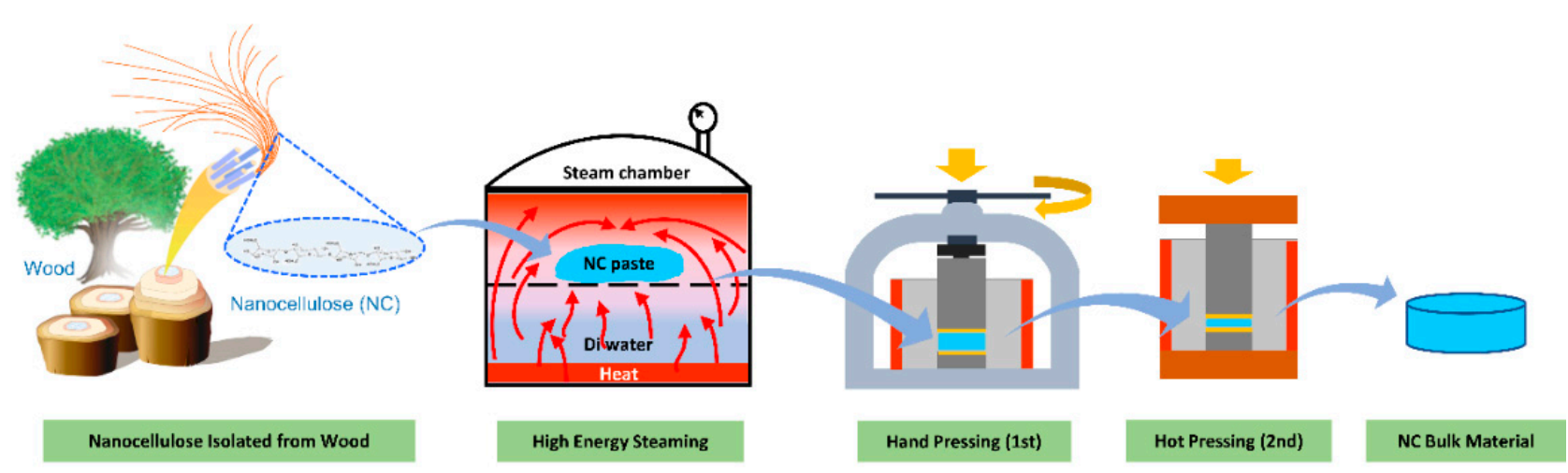

Figure 1. Schematic of nanocellulose bulk material fabrication process.

\section{Experiment}

\subsection{Materials}

CNC powder was purchased from Celluforce, Montreal, Canada. It was produced by the spray drying method, and the moisture content was 4-6 wt \%. Deionized (DI) water was used for the preparation of CNC pastes.

\subsection{Methods}

\subsubsection{Processing of NC Bulk Material}

The CNC powder was mixed with DI water (40 wt $\%$ ), and the mixed NC paste was taken for steam treatment in a pressurized steam pot at a temperature of $120{ }^{\circ} \mathrm{C}$ and a pressure of 2 bar for $30 \mathrm{~min}$. The steamed NC paste was used for hot press molding to form circular disc shapes. The hot press mold consisted of a circular rod and a circular-hole die made with stainless steel, and its process was composed of two stages: hand pressing and hot pressing. Figure 1 shows the molding process of the NC bulk material. The hand pressing stage involves pre-pressing before the hot pressing to form an initial shape of the specimen with a gentle press. For the pre-pressing, first, Kapton tape was attached to the end of the circular rod, on which the NC paste contacted to release the NC paste quickly. A band heater was installed around the die to apply heat, and then the press mold was heated at $50{ }^{\circ} \mathrm{C}$ for more than $10 \mathrm{~min}$ to maintain sufficient heat in the press mold. After filling the NC paste into the mold, the rod was pressed with a screw, and the applied press load was monitored using a load cell (CMCS-10T, Bongshin, Osan-si, South Korea). The press mold was also heated using the band heater, with the temperature maintained at 80 , 90 , and $100{ }^{\circ} \mathrm{C}$ within a specific time limit. After the hand pressing stage, hot pressing was performed using a hot press machine (SB3651, HY Industry Co., Incheon, South Korea) for applying high pressure to densify the NC paste and finish the forming. During hot pressing, the band heater was also used for heating the press mold in conjunction with the hot press machine.

After processing, the NC bulk material was formed in a circular disk shape. Table 1 shows the complete process conditions in terms of time, temperature, and pressure. The non-steamed NC paste was also tested for comparison. The time required for each process varied slightly. The molded NC bulk material specimens' density ranged from $\delta=1.7-1.8 \mathrm{~g} / \mathrm{cm}^{3}$. 
Table 1. Pressing condition of nanocellulose bulk material fabrication.

\begin{tabular}{|c|c|c|c|c|c|c|c|}
\hline \multirow{2}{*}{\multicolumn{2}{|c|}{ Press Molding Condition }} & \multicolumn{3}{|c|}{ Without Steam Process } & \multicolumn{3}{|c|}{ With Steam Process } \\
\hline & & $80^{\circ} \mathrm{C}$ & $90{ }^{\circ} \mathrm{C}$ & $100{ }^{\circ} \mathrm{C}$ & $80^{\circ} \mathrm{C}$ & $90{ }^{\circ} \mathrm{C}$ & $100{ }^{\circ} \mathrm{C}$ \\
\hline \multirow{2}{*}{ Hand pressing } & Time & $8 \mathrm{~h}$ & $7 \mathrm{~h}$ & $6 \mathrm{~h}$ & $8 \mathrm{~h}$ & $7 \mathrm{~h}$ & $6 \mathrm{~h}$ \\
\hline & Max. pressure & \multicolumn{6}{|c|}{$20 \mathrm{MPa}$} \\
\hline \multirow{2}{*}{ Hot pressing } & Time & & $20 \mathrm{~h}$ & & & $24 \mathrm{~h}$ & \\
\hline & Max. pressure & \multicolumn{6}{|c|}{$60 \mathrm{MPa}$} \\
\hline
\end{tabular}

\subsubsection{Machining of NC Bulk Material}

The machining experiments were conducted on the CNC bulk material specimen using an end mill. The specimen dimensions were $13 \times 15 \times 1.8 \mathrm{~mm}^{3}$ (length $\times$ width $\times$ height), cut out from the molded circular disk. A machine tool (Unimat Eduset, The Cool Tool, Modling, Austria) was used for the milling operation with a spindle speed between 1100-4000 rpm without cutting lubricant. The end mill tool was selected for the 4 flutes square HSS cobalt tool with a $3 \mathrm{~mm}$ diameter (YG1, Incheon, Korea). A new tool was used for each sample to prevent tool wear. The cutting spindle speed for end milling was set to 3 levels: 1200, 2560, and $4000 \mathrm{rpm}$. The feed speed ranged between $0.32-5 \mathrm{~mm} / \mathrm{s}$, and the cutting depth was $0.5 \mathrm{~mm}$. A vacuum cleaner suctioned the chip to eliminate heat accumulation in the cutting zone [22]. The specimens were cut by a single path along the feed direction to prevent the influence of several cutting paths.

\subsubsection{Characterization}

Surface and cross-section morphologies of the steam-treated and non-steamed NC bulk materials were taken using field emission scanning electron microscopy (FESEM, S-3000, Hitachi, Tokyo, Japan). The samples were fabricated at $100{ }^{\circ} \mathrm{C}$. X-ray diffraction (XRD, X'pert PRO MRD, Malvern Panalytical, Malvern, UK) was carried for investigating the crystallinity of the bulk materials. The XRD samples were prepared for four cases: (i) CNC powder, (ii) CNC powder compaction without DI water mixing, (iii) non-steamed and fabricated at $100^{\circ} \mathrm{C}$, and (iv) steam-treated and fabricated at $100^{\circ} \mathrm{C}$. A dynamic mechanical analyzer (DMA, Q800, TA Instruments, New Castle, DE, USA) was used for measuring the frequency-dependent mechanical properties using a three-point bending test. Six cases of the NC bulk materials for steamed/non-steamed were prepared at 80,90 , and $100{ }^{\circ} \mathrm{C}$. The NC bulk material specimens were cut into a $12 \mathrm{~mm}$ width and a $15 \mathrm{~mm}$ length for the three-point bending tests. The frequency range was 1 to $100 \mathrm{~Hz}$ at ambient temperature and humidity conditions.

The surface roughness was measured at three points along the feed direction at intervals of $5 \mathrm{~mm}$, the top, middle, and bottom parts, using a surface roughness profiler (Zygo NewView7000, Lambda Photometrics, Hertfordshire, UK). The arithmetic average roughness, $R_{a}$, was calculated to characterize the machined surface finish quality. A thermal imaging camera (B620, FLIR, Stockholm, Sweden) was used to monitor the machining temperature. The thermal imaging camera was positioned $50 \mathrm{~cm}$ away from the specimen.

\section{Results and Discussion}

\subsection{NC Bulk Material Characterization}

The morphologies of the bulk materials, including both steam and non-steam process samples, were investigated using FESEM. Figure 2a,c shows the surface images for bulk materials fabricated at $100{ }^{\circ} \mathrm{C}$ with non-steam and steam processing. Figure $2 b$,d represents their cross-sectional images. The non-steam-processed sample showed a layered structure within the cross-section. Meanwhile, the steam-processed sample exhibited a combination of a layered structure and a blended one. 

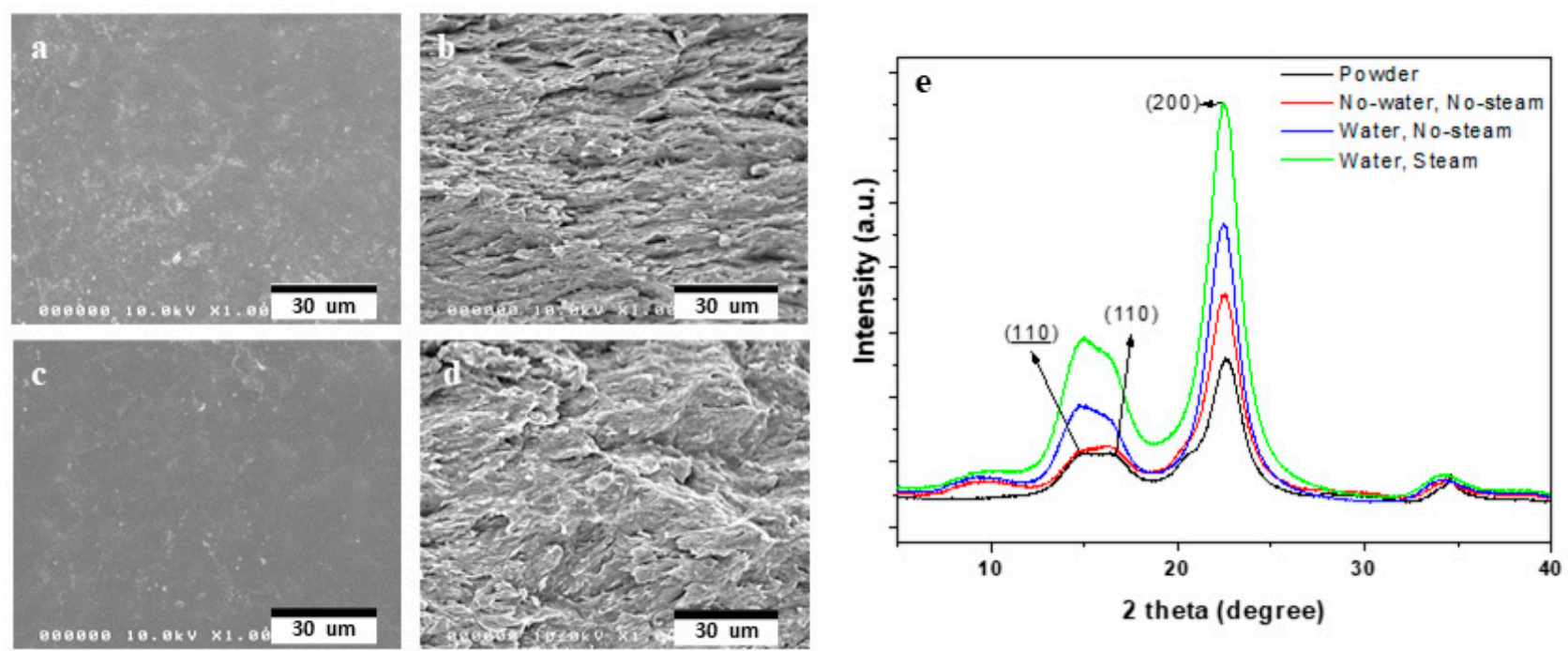

Figure 2. (a) Surface and (b) cross-section SEM images of non-steam processed bulk material, (c) surface and (d) cross-section SEM image of steam-processed bulk material, and (e) XRD results of the four cases: CNC powder (Powder), only CNC powder compaction (No-water, No-steam), non-steam-processed after mixing CNC powder and DI water (Water, No-steam) and steam-processed after mixing CNC powder and DI water (Water, Steam).

XRD was used to identify the crystalline structure of the bulk material. Figure 2e shows the XRD results of the four cases: (i) CNC powder, (ii) only CNC powder compaction without mixing, (iii) non-steam-processed after mixing CNC powder and DI water, and (iv) steam-processed after mixing CNC powder and DI water. For the CNC powder, the peaks that appeared at $2 \theta=14.7^{\circ}, 16.4^{\circ}$, and $22.6^{\circ}$ represent the characteristic peaks of cellulose I. The $22.6^{\circ}$ peak of the (200) plane shifted to a lower angle for the steam-processed case. This means that the interplanar spacing and the lattice constant increased because of the compression stress. The crystallinity of the samples was calculated using Equation (1), with the maximum value of $2 \theta=22.6^{\circ}\left(I_{200}\right)$ and the minimum value of $2 \theta=18^{\circ}\left(I_{a m}\right)$ between the (110) plane and the (200) plane.

$$
C r I=\frac{I_{200}-I_{a m}}{I_{200}} \times 100 \%
$$

The CrI calculation result indicated that the crystallinity degree increased from $73.4 \%$ to $80.8 \%$ by steam processing. This means that the lattice arrangement increased inside the bulk material with an accumulation of hydrogen bonds among CNC via steam processing, which led to an increase in dynamic modulus.

Figure 3 shows the three-point bending test results for the steam treated and nonsteamed samples. The specimens were fabricated at 80,90 , and $100{ }^{\circ} \mathrm{C}$. In all samples, the resonance frequency appeared near $80 \mathrm{~Hz}$. The steam-treated specimens showed slightly higher storage modulus and loss modulus than the non-steamed specimens at the same fabrication temperature. In addition, the storage modulus increased with increasing the fabrication temperature, and the loss modulus also increased proportionally with increasing temperature, as shown in Figure 3a-d. The loss moduli gradually increased with the frequency in all cases below the resonance frequency associated with materials damping. The loss modulus of the specimen treated at $90^{\circ} \mathrm{C}$ increased more with increased frequency than did the specimens treated at 80 and $100{ }^{\circ} \mathrm{C}$ (Figure $3 \mathrm{~b}, \mathrm{~d}$ ). This might be associated with water molecules in CNCs. There are two kinds of water molecules in CNC bulk materials: free and adsorbed water molecules. Free water molecules can be easily removed once the specimens are heated over $100{ }^{\circ} \mathrm{C}$, whereas adsorbed water molecules can remain in the bulk materials. The specimens treated at 80 and $90^{\circ} \mathrm{C}$ might have more free water molecules, which are more sensitive to frequency. 

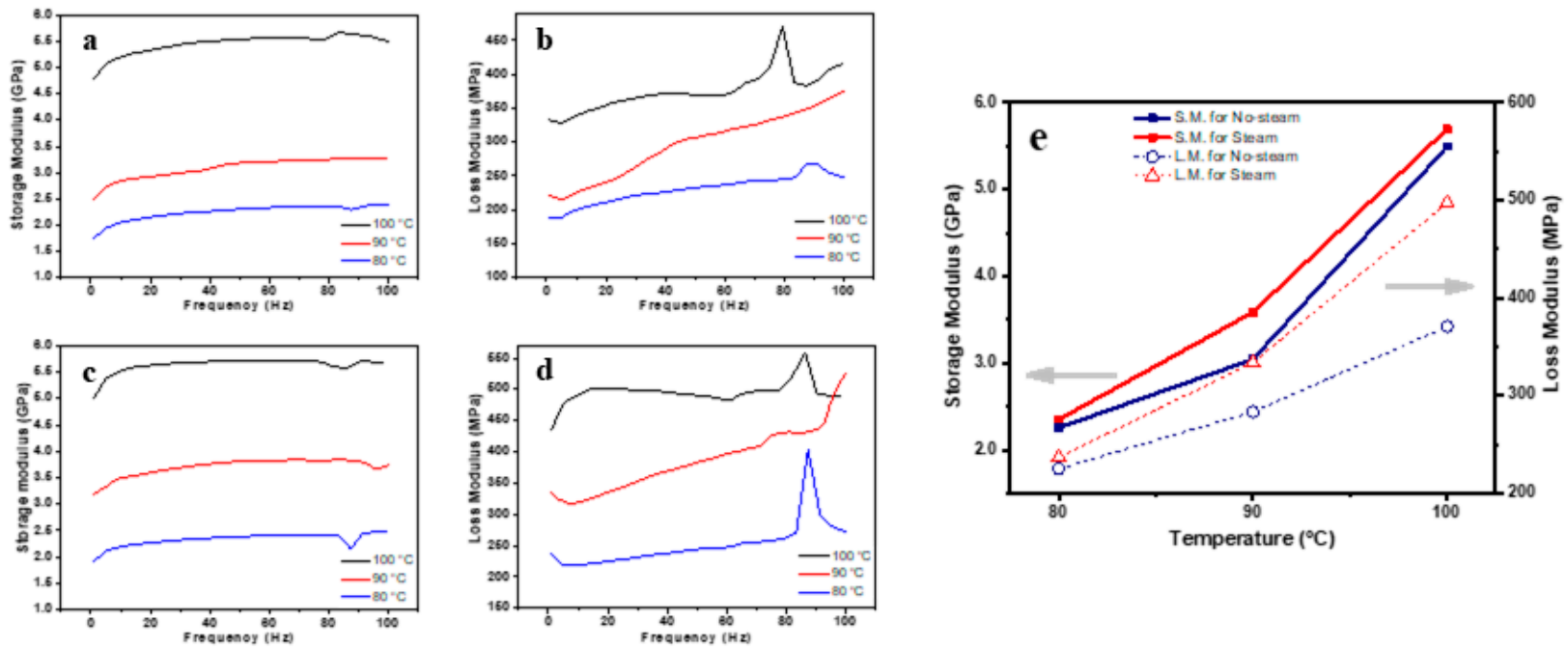

Figure 3. (a) Frequency-dependent storage modulus and (b) loss modulus for the no-steam processed bulk materials; (c) storage modulus and (d) loss modulus for the steam processed bulk materials fabricated at 80,90 , and $100{ }^{\circ} \mathrm{C}$; (e) recap of storage and loss moduli with temperatures at $38 \mathrm{~Hz}$.

Figure 3e shows the recap of storage and loss moduli of the NC bulk materials with different temperatures at $38 \mathrm{~Hz}$. In particular, the highest value of the specimen's storage modulus at $100{ }^{\circ} \mathrm{C}$ with steam treatment was approximately $5.7 \mathrm{GPa}$, about twice as high as that of engineering plastics such as polycarbonate [23]. From the storage and loss moduli, $\tan \delta$ was calculated, and Figure S1 shows the results. Peaks of $\tan \delta$ were shown over $80 \mathrm{~Hz}$, which might be associated with the specimens' resonance frequencies. With increasing hot-pressing temperature, the $\tan \delta$ decreased, and an average value of 0.085 was approached when the temperature was $100^{\circ} \mathrm{C}$. This value is higher than that of ceramics, which is 0.05 [24]. Such a high $\tan \delta$ is beneficial for reducing structure-borne noise and vibrations. Thus, it can be said that NC bulk materials have good elastic modulus with suitable damping properties. Note that the hot-pressing temperature was limited to $100{ }^{\circ} \mathrm{C}$ because of cellulose's thermal degradation limit.

\subsection{Machining Characteristics}

After forming NC bulk material by press molding, this material should be machinable to manufacture a delicate part. Thus, machining of the press-molded NC materials was tested. Since a slow feed speed with a high cutting spindle speed gives a better surface finish, the fastest spindle speed at each feed speed was selected. Table S1 in Supplementary Materials shows the surface roughness results of the machined NC bulk materials. The best surface roughness of $0.724 \mu \mathrm{m}$ was observed when the feed speed was $1.25 \mathrm{~mm} / \mathrm{s}$ and the spindle speed was $4000 \mathrm{rpm}$, as shown in Figure $4 \mathrm{~d}$.

It is worth noting that the measured surface roughness was not comparable with a general metal machined surface. Unusually, a slower feed speed did not improve the surface roughness. Nevertheless, the surface roughness was far better than that obtained using end mill machining on polymer composites [25-28]. However, it is difficult to generalize the surface roughness value because surface roughness is determined by many factors, such as the type of workpiece materials, tool materials, tools, and machining conditions. 


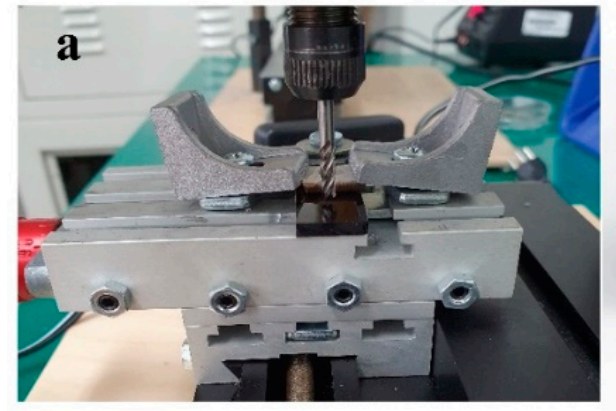

d

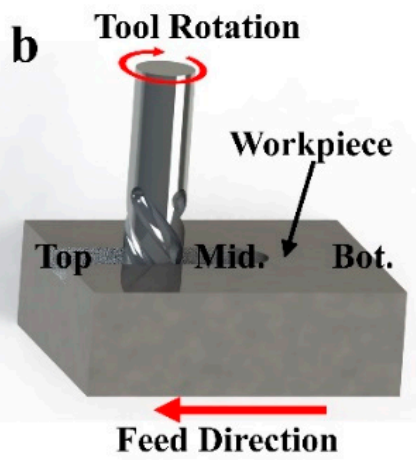

Feed Direction

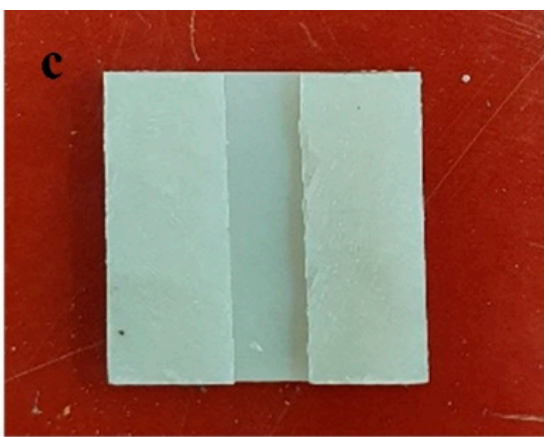

e
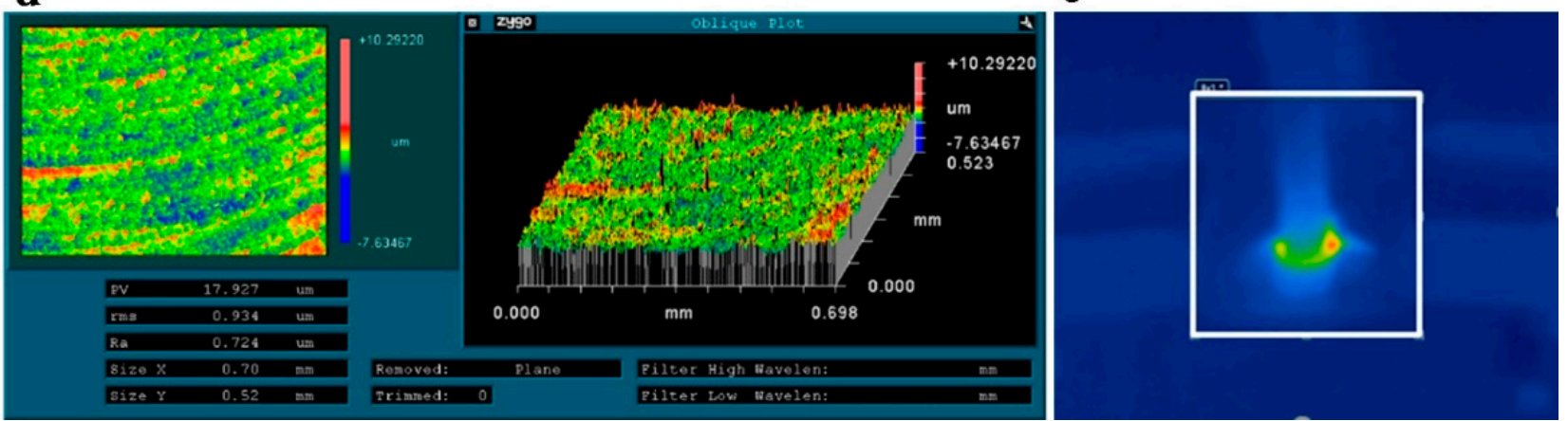

Figure 4. (a) Photograph of the setup for end mill machining, (b) schematic of the end mill machining for feed direction and machining location, (c) machined nanocellulose bulk material, (d) representative image of surface roughness, and (e) thermal image of machining $(1.25 \mathrm{~mm} / \mathrm{s}$ feed speed and $4000 \mathrm{rpm}$ spindle speed).

Temperature rise during the machining was investigated using a thermal imaging camera, and Figure $4 \mathrm{e}$ shows the maximum temperature rise. The temperature during machining generally increased with the spindle speed and feed speed. The highest temperature of $56.5^{\circ} \mathrm{C}$ was measured at a $1.25 \mathrm{~mm} / \mathrm{s}$ feed speed and a $4000 \mathrm{rpm}$ spindle speed. The temperature rises indicate that the maximum temperature is much lower than the cellulose decomposition temperature [7]. In other words, there was no thermal degradation of the NC bulk material during the machining.

\section{Conclusions}

An NC bulk material was manufactured using steam treatment and hot press molding on cellulose nanocrystals without using any binder. The morphologies were studied using FESEM and XRD, and the mechanical properties were examined using DMA. The steamprocessed sample exhibited a combination of a layered structure and a blended one. The interplanar spacing and the steam-processed sample's lattice constant increased because of the compression stress and the crystallinity degree of the steam processing. The NC bulk material exhibited mechanical properties comparable to those of engineering plastics and polycarbonate.

Furthermore, the NC bulk materials' machinability was investigated by measuring their surface roughness. The temperature rise observation of the machined surface during the end mill processing showed no material degradation during the machining. In summary, the steam-treated and hot press molded NC bulk material has the potential to be an environment-friendly material that can substitute plastics.

Supplementary Materials: The following are available online at https:/ /www.mdpi.com/article/10 .3390 / cryst11080853/s1, Figure S1: Frequency-dependent tan $\delta$ results: (a) non-steam processed bulk materials and (b) steam-processed bulk materials fabricated at 80,90 and $100{ }^{\circ} \mathrm{C}$, Table S1: Results of the machining of NC bulk materials with various conditions. 
Author Contributions: Conceptualization, J.K.; methodology, J.-W.K. and D.O.A.; validation, H.C.K.; resources, L.Z.; writing-original draft preparation, J.-W.K.; writing-review and editing, H.-C.K. and J.K.; supervision, J.K. All authors have read and agreed to the published version of the manuscript.

Funding: This research was funded by the Creative Research Initiatives Program through the National Research Foundation of Korea (NRF-2015R1A3A2066301).

Data Availability Statement: Not applicable.

Conflicts of Interest: The authors declare no conflict of interest.

\section{References}

1. Van, V.L.H.; Balise, P.L.; Van, V.L.H.; Balise, P.L. Elements of materials science. Phys. Today 1959, 12, 52-53. [CrossRef]

2. Eriksen, M.; Lebreton, L.C.; Carson, H.S.; Thiel, M.; Moore, C.J.; Borerro, J.C.; Galgani, F.; Ryan, P.G.; Reisser, J. Plastic pollution in the world's oceans: More than 5 trillion plastic pieces weighing over 250,000 tons afloat at sea. PLoS ONE 2014, 9, e111913. [CrossRef] [PubMed]

3. Meier, M.A.R. Renewable resources for polymer chemistry: A sustainable alternative? Macromol. Rapid Commun. 2011, 17, 1297-1298. [CrossRef]

4. Hamad, W.Y. Cellulose Nanocrystals: Properties, Production and Applications; Wiley: Chichester UK, 2017.

5. Roman, M. Toxicity of cellulose nanocrystals: A review. Ind. Biotechnol. 2015, 11, 25-33. [CrossRef]

6. $\mathrm{Wu}, \mathrm{Z}$; $\mathrm{Xu}$, J.; Gong, J.; Li, J.; Mo, L. Preparation, characterization and acetylation of cellulose nanocrystal allomorphs. Cellulose 2018, 25, 4905-4918. [CrossRef]

7. Moud, A.A.; Arjmand, M.; Liu, J.; Yang, Y.; Sanati-Nezhad, A.; Hejazi, S.H. Cellulose nanocrystal structure in the presence of salts. Cellulose 2019, 26, 9387-9401. [CrossRef]

8. Asadi, A.; Miller, M.; Sultana, S.; Moon, R.J.; Kalaitzidou, K. Introducing cellulose nanocrystals in sheet molding compounds (SMC). Compos. Part A Appl. Sci. Manuf. 2016, 88, 206-215. [CrossRef]

9. Nechyporchuk, O.; Belgacem, M.N.; Bras, J. Production of cellulose nanofibrils: A review of recent advances. Ind. Crops. Prod. 2016, 93, 2-25. [CrossRef]

10. Yao, Y.; Tao, J.; Zou, J. Light management in plastic-paper hybrid substrate towards high-performance optoelectronics. Energy Environ. Sci. 2016, 9, 2278-2285. [CrossRef]

11. Li, T.; Zhai, Y.; He, S.; Gan, W.; Wei, Z.; Heidarinejad, M.; Dalgo, D.; Mi, R.; Zhao, X.; Song, J.; et al. A radiative cooling structural material. Science 2019, 364, 760-763. [CrossRef] [PubMed]

12. Cao, D.; Xing, Y.; Tantratian, K.; Wang, X.; Ma, Y.; Mukhopadhyay, A.; Cheng, Z.; Zhang, Q.; Jiao, Y.; Chen, L.; et al. 3D printed high-performance lithium metal microbatteries enabled by nanocellulose. Adv. Mater. 2019, 31, 1807313. [CrossRef] [PubMed]

13. Zhang, Y.; Zhang, L.; Cui, K.; Ge, S.; Cheng, X.; Yan, M.; Yu, J.; Liu, H. Flexible Electronics Based on Micro/Nanostructured Paper. Adv. Mater. 2018, 30, 1801588. [CrossRef] [PubMed]

14. Wang, Q.; Yao, Q.; Liu, J.; Sun, J.; Zhu, Q.; Chen, H. Processing nanocellulose to bulk materials: A review. Cellulose 2019, 26, 7585-7617. [CrossRef]

15. Dufresne, A. Processing of nanocellulose-based materials. In Nanocellulose; De Gruyter: Boston, MA, USA, 2017; pp. 351-418. [CrossRef]

16. Pintiaux, T.; Viet, D.; Vandenbossche, V.; Rigal, L.; Rouilly, A. High Pressure Compression-Molding of $\alpha$-Cellulose and Effects of Operating Conditions. Materials 2013, 6, 2240-2261. [CrossRef] [PubMed]

17. Rol, F.; Rouilly, A.; Bras, J. Thermo-compression of cellulose nanofibrils. Cellulose 2020, 27, 25-40. [CrossRef]

18. Kam, D.; Layani, M.; BarkaiMinerbi, S.; Orbaum, D.; BenHarush, S.A.; Shoseyov, O.; Magdassi, S. Additive Manufacturing of 3D Structures Composed of Wood Materials. Adv. Mater. Technol. 2019, 4, 1900158. [CrossRef]

19. Startsev, O.V.; Salin, B.N.; Skuridin, Y.G.; Utemesov, R.M.; Nasonov, A.D. Physical properties and molecular mobility of the new wood composite plastic "thermobalite". Wood Sci. Technol. 1999, 33, 73-83. [CrossRef]

20. Kajikawa, S.; Iizuka, T. Influence of Steaming and Boiling at $180^{\circ} \mathrm{C}$ Plus on the Injectability of Bamboo Powder. Key Eng. Mater. 2013, 554, 1856-1863. [CrossRef]

21. Berglund, L.A.; Peijs, T. Cellulose Biocomposites-From Bulk Moldings to Nanostructured Systems. MRS Bull. 2010, 35, 201-207. [CrossRef]

22. Enemuoh, E.U.; El-Gizawy, A.S.; Okafor, A.C. An approach for development of damage-free drilling of carbon fiber reinforced thermosets. Int. J. Mach. Tools Manuf. 2001, 41, 1795-1814. [CrossRef]

23. Bilyk, S.R.; Scheidler, M.J. Mechanical Response and Shear Initiation of Double-Base Propellants. In Proceedings of the 13th International Detonation Symposium, Norfolk, VA, USA, 23-28 July 2006.

24. Chandrasekhar, M.; Kumar, P. Processing and characterizations of BNT-KNN ceramics for actuator applications. Process Appl. Ceram. 2016, 10, 73-77. [CrossRef] 
25. Konneh, M.; Izman, S.; Dzahi Padil, M.E.; Roszat, R. Surface Roughness Study of Milled Carbon Fiber Reinforced Polymer (CFRP) Composite Using $4 \mathrm{~mm}$ 2-Flute Titanium Aluminum Nitride (TiAlN) Coated Carbide End Mills. Adv. Mater. Res. 2014, 887, 1101-1106. [CrossRef]

26. Geier, N.; Pereszlai, C. Analysis of Characteristics of Surface Roughness of Machined CFRP Composites. Period Polytech. Mech. Eng. 2020, 64, 67-80. [CrossRef]

27. Ridwan, F.; Havendri, R.; Susanti, O. Analysis cutting forces and surface roughness of fibre reinforced polymer for end mill processes. IOP Conf. Ser. Mater. Sci. Eng. 2019, 602, 12083. [CrossRef]

28. Tomadi, S.H.; Ghani, J.A.; Haron, C.H.C.; Ayu, H.M.; Daud, R. Effect of Cutting Parameters on Surface Roughness in End Milling of AlSi/AlN Metal Matrix Composite. Procedia Eng. 2017, 184, 58-69. [CrossRef] 